\title{
Editorial
}

\section{El desafío de El Salvador después de los terremotos}

Los terremotos han dejado a El Salvador ante el desafío de cómo continuar. Si la transición de postguerra estaba ya agotada en la práctica, los terremotos le han puesto fin, al colocar un parte aguas. Con ellos, El Salvador entra en otra etapa de su historia, la cual coincide con el inicio del milenio. Como habrá un antes y un después de los terremotos, la cuestión a debarir es qué clase de después es el que viene. Bastaron poco menos de cincuenta segundos para poner fin de una sola vez a la realidad anterior y dejar a El Salvador enfrentado a una muy realidad distinta, más compleja y difícil. Lo que más llama la atención, sin duda, es la destrucción física de un tercio de la vivienda de la población salvadoreña y de una parte importante de la infraestructura del país. Ambas cosas deberán ser reemplazadas, pero del cómo se haga depende la configuración que adquiera esta etapa, que ahora estaría comenzando.

Es obligado, por lo tanto, debarir cómo se configura este después de los terremoros, sobre todo de cara a quienes en el gobierno y la gran empresa privada pretenden orientarlo a reconstruir lo perdido y a retomar la misma dirección anterior y desde la perspectiva de quien busca aprovechar las circunstancias para intentar construir algo diferente, en la línea de crear una sociedad más segura y equitariva, donde puedan desarrollarse hombres y mujeres más responsables y solidarios. Hasta ahora, el debare público ha sido dominado por la urgencia de encontrar financiamiento para enfrentar el desafío y de reunir todas las energías y voluntades en torno a una gran unidad nacional. Sin duda, ambas cosas son indispensables para seguir adelante después de los terremotos, pero esa unidad debe construirse alrededor de un proyecto que, al recoger las aspiraciones de la colectividad, invire a sumarse a él. De esta manera, el cómo seguir adelante está intrínsecamente relacionado con la unidad. El Salvador no ha entrado en esta fase de su historia de manera voluntaria, sino que ha sido forzado a entrar en ella por los terremotos; tampoco es completamente libre para decidir su futuro, sino que está forzado por su pasado 
inmediato y por fuerzas externas que no controla. La cuestión es cómo convertir estas imposiciones de la realidad en oportunidades para el cambio social.

\section{La ideología del progreso y del anticomunismo}

La reunión del grupo consultivo, que el Banco Interamericano de Desarrollo convocó en Madrid, a comienzos de marzo, en continuidad con la tenida hace varios años en Estocolmo, después del huracán Mitch, llamó la atención en El Salvador por dos cuestiones: la representatividad del gobierno y la cantidad de dinero necesaria para financiar la etapa posterior a los terremotos. La polémica surgida por el intento fallido de no incluir a nadie más que a funcionarios en la delegación gubernamental y la especulación sobre los millones de dólares que podrían conseguirse, desviaron la atención del para qué de dicha reunión y sobre todo del cómo se emplearía ese dinero. Esta es una cuestión de largo plazo mucho más importante que las dos primeras, porque es la que determinará, en última instancia, cómo se invertirá el financiamiento otorgado y, en consecuencia, cómo será configurada la sociedad salvadoreña.

La cuestión se encuentra recogida en el documento titulado Unidos por El Salvador. Plan de recuperación de los daños causados por los terremotos del 13 de enero y 13 de febrero de 2001. Dos ideas llaman la atención en este documento. La primera se refiere al concepto que el gobierno tiene del proceso hisrórico salvadoreño y la segunda, estrechamente relacionada con ésta, es la visión del país que desearía construir. Según el gobierno, los terremoros, a los cuales considera como simples fenómenos naturales, habrían "complicado enormemente" el proceso de desarrollo salvadoreño, un proceso que, según esta interpretación simplista, marchaba sin ninguna dificultad. No obstante esta "complicación", "el pueblo salvadoreño" —en un deslizamiento conceptual injustificable identifica gobierno con pueblo- se mantiene firme en su propósito de "desarrollar una sociedad integrada consigo misma y con el mundo en general", cuyos fundamentos serían consolidar la democracia, luchar contra la pobreza, la parricipación ciudadana y el desarrollo económico, a través de una economía abierta de mercado. En teoría, estos retos parecen razonables; pero, es obligado revisarlos desde los terremotos, no tanto desde lo que prometen, sino desde el modo cómo se propone alcanzar esas metas. No se trata de un simple descuido, sino de que el gobierno salvadoreño cree que los terremotos no han alterado en nada la realidad. Ni siquiera toma nota de la revelación de cuán poco se había avanzado por los caminos del desarrollo humano y de cuán endebles son los pocos logros ya conseguidos. En definitiva, los terremotos quedan reducidos a "una complicación" intrascendente.

La visión que de El Salvador tiene el gobierno de ARENA y de la cual deriva las propuestas presentadas en Madrid individualmente y como parte de la región centroamericana, es la de un país dotado con una infraestructura moderna, con una producción diversificada y competitiva y con unos servi- 
cios públicos universales. De esta manera, la mejora en la calidad de vida de sus habitantes sería continua y la conservación del medio ambiente estaría asegurada. El énfasis de esta visión está puesto en el desarrollo tecnológico y en la producción y sólo de una manera indirecta en la satisfacción de las necesidades del millón y medio de damnificados. La lógica de la visión sostiene que la tecnología aumentará la producción y ésta el empleo, el cual llevará los ingresos necesarios a las familias salvadoreñas. La misma lógica se encuentra en la propuesta regional, en la cual se habla de transformación y modernización, a través de la creación del corredor Puebla (México)-Panamá. Esta perspectiva presenta, sin embargo, tres dificultades. La primera es que hasta ahora, El Salvador no ha dado ninguna importancia al desarrollo tecnológico, el cual es fundamental para la ejecución de los planes gubernamentales. La Comisión Nacional de Ciencia y Tecnología, la entidad pública encargada de promover la investigación, no ha cumplido con su papel. El gobierno tampoco ha mostrado interés alguno por el desarrollo de la investigación y de la tecnología en las universidades. La segunda dificultad es que el plan Puebla-Panamá está más interesado en el desarrollo del sur de México que en el de Centroamérica. $Y$, finalmente, la rercera dificultad es el beneficiario directo, que no son los damnificados, sino el gran capital nacional y transnacional. Los damnificados tendrían que conformarse con aguardar los beneficios indirectos de la actividad del capital. Aquellos que quedaran excluidos o aquellos cuyos ingresos no fueran suficientes para satisfacer sus necesidades básicas, serían arendidos a través de programas especiales de asistencia pública.

No obstante, Unidos por El Salvador habla de la "construcción de un nuevo El Salvador" en cinco años, al final de los cuales será "menos vulnerable

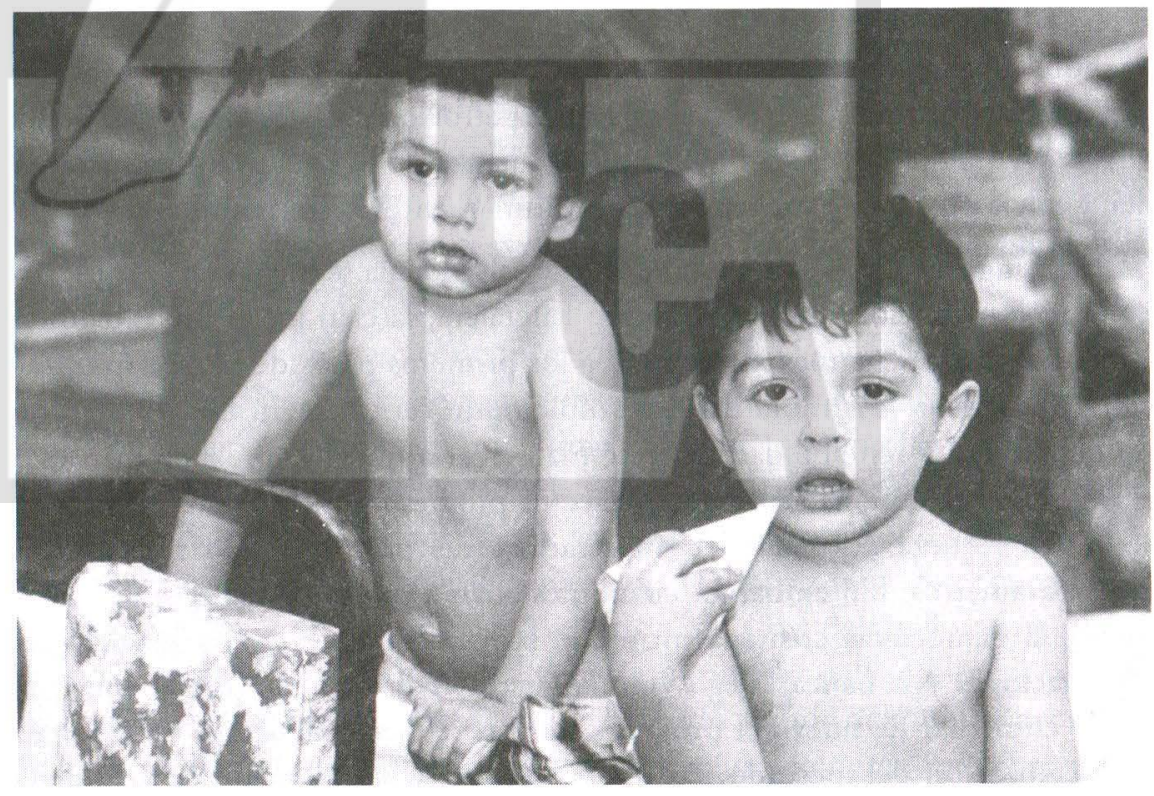


socialmente y más equitativo, justo, participativo e integrado"; también establece, sin lugar a duda alguna, que "las condiciones que han permitido gozar de estabilidad económica deben mantenerse, ya que son indispensables para conseguir recursos externos, propiciar el desarrollo y garantizar el bienestar a la población". Esto último significa que la política económica no experimentará modificación alguna a raíz de los terremotos, aun cuando en una década no ha conseguido ninguno de esos tres objetivos: los recursos externos necesarios para hacer crecer la economía en el volumen requerido para reducir eficazmente la pobreza todavía no han arribado; el crecimiento económico, fundamental para el desarrollo humano, tiende más bien a ser bajo —aun cuando en la primera parte de la década de 1990 mostró la tendencia inversa- y, en la actualidad, se produce menos que antes y a un costo mucho más elevado, y tal como los terremotos han sacado a luz, la mayoría de la población no vive en el bienestar, sino en la pobreza y en la pobreza extrema.

Cabe preguntarse, entonces, por qué mantener este planteamiento, aun cuando ya ha demostrado de una forma incuestionable que las metas que propone son inalcanzables, en lugar de aprovechar la coyuntura abierta por los terremotos para intentar una alternativa más eficaz de cara a conseguir las metas propuestas. La respuesta es tan simple como el planteamiento mismo. ARENA cree que El Salvador progresa de manera automática y autónoma; lo que se haga o deje de hacer es indiferente, el país siempre continuará por la senda del progreso. Por eso, tragedias como los terremotos no son más que inconvenientes, que pueden retrasar, pero nunca impedir el progreso, cuyo éxito estaría asegurado. Esta idea de progreso caracteriza a la elite salvadoreña desde hace más de un siglo. Desde entonces, la elite cree que el progreso está poseído de una fuerza inagotable y que, además, es imparable. Según su creencia, El Salvador estaría progresando desde finales del siglo XIX, aun cuando se ha encontrado con algunos obstáculos como la depresión de 1930 y el alzamiento rural de 1932, la crisis del petróleo de la década de 1970 y la guerra civil de la de 1980, incluyendo la alianza de la Fuerza Armada con la democracia cristiana y sus reformas. Y, últimamente, los terremotos.

Esta singular idea de progreso de la elite salvadoreña se fraguó en el contexto de la racionalización de la producción cafetalera, la cual luego fue extendida a otros cultivos de agroexportación y a los primeros pasos de la industrialización, dados bajo la sombra del mercado común centroamericano. La elevada productividad y rentabilidad del café hizo creer a quienes lo explotaban que el progreso era cosa hecha. Para este sector progreso significa ganar mucho y acumular riqueza. El éxiro del empresario y del país lo mide de acuerdo a estos parámetros. Sin embargo, cuando estaban a punto de hacer realidad su sueño, la democracia cristiana introdujo la reforma agraria y nacionalizó las exportaciones y la banca; luego vino la guerra civil. Cristiani fue el encargado de encarrilar de nuevo el progreso con sus reformas de ajuste estructural, la liberalización del mercado, las privatizaciones y la exaltación de la indivi- 


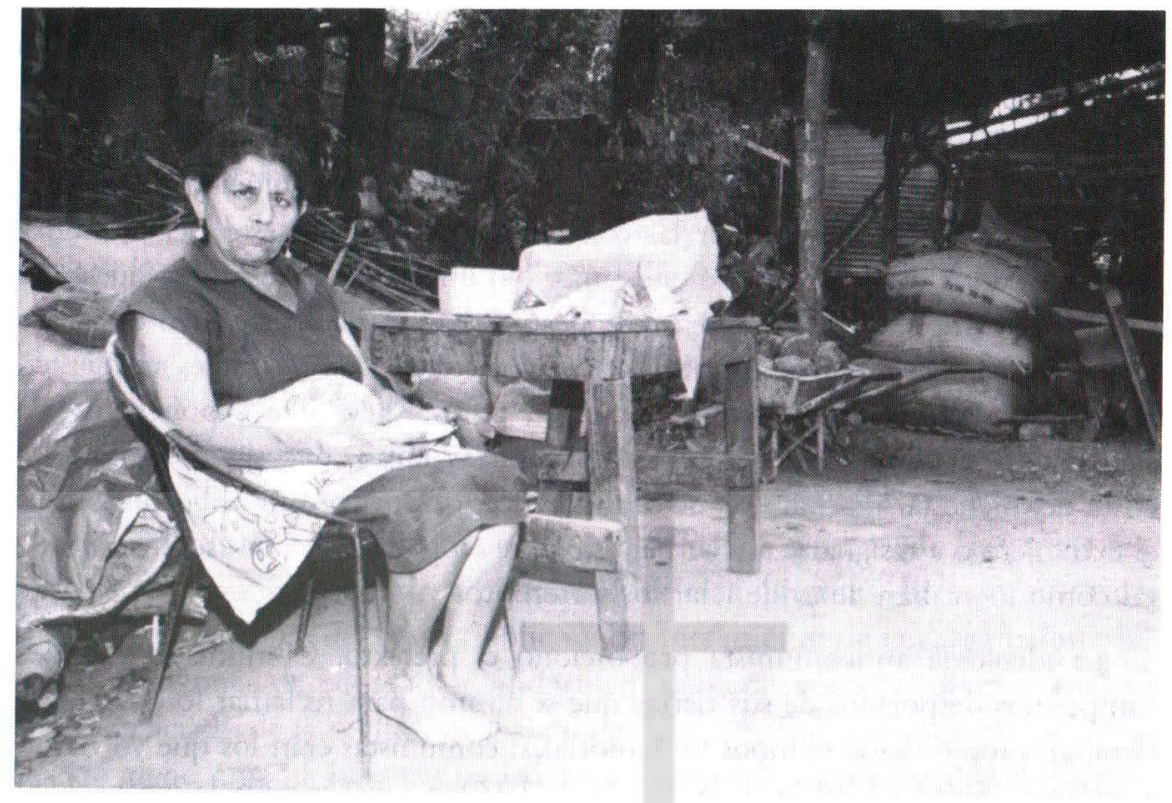

dualidad. Así, la creencia en el progreso adquirió de nuevo carácter de certe$z a$, esta vez de la mano del neoliberalismo. Y de nuevo, cuando estaban a punto de alcanzar las metas de la prosperidad y del bienestar, cuando El Salvador parecía nuevo, los terremotos han venido a complicar la situación.

Aparte de complicar las certezas de la clase dominante, los terremotos se han encargado de exponer la verdad de su idea de progreso: sólo progresa la ciudad y no el campo, y en la ciudad, sólo el quintil donde se concentran los ingresos más altos. Por eso, se equivocan quienes sostienen que la polarización es exclusivamente política. Antes que la polarización política está la económica y social. Aquélla es sólo una consecuencia de ésta. Hasta ahora, la contradicción implícica en esic progreso que, en lugar de ampliarse para incluir a más sectores sociales, se ha vuelto cada vez más excluyente y exclusivo, que mientras alaba ciertas virtudes de la población salvadoreña, como su laboriosidad, la explota de manera despiadada, se ha podido mantener con la participación activa del ejército, de la gucrra y de la propaganda.

la ideología del progreso exige silencio y olvido. Todo aquello que la cuestiona o la contradice es desechado como irrelevante o motivado por el resentimiento o la ambición ilegítima o, en último término, por fuerzas extrañas, que vendrían a perturbar la prosperidad y la felicidad de la gran familia salvadoreña. La masacre de 1932 fue erradicada de las fuentes nacionales y sólo se habla de ella por estricta necesidad $y$, por lo general, de una forma muy distorsionada. La guerra civil también es tergiversada en sus causas y sus desarrollos; aunque se reconoce su existencia, se riende a restarle importancia y se intenta ocultar sus crueldades y asesinaros. El silencio y el olvido no son sólo un recurso para conservar la estabilidad del orden establecido, sino una necesidad. El progreso 
en el que tanto cree la clase dominante salvadoreña ha dejado en el camino a varias decenas de miles de campesinos asesinados en 1932. En las décadas de 1970 y 1980, volvió a asesinar masivamente. A comienzos de la década de 1980 , los grandes terratenientes hablaban abiertamente de que la solución de los problemas del país era interrumpir las comunicaciones con el resto del mundo y asesinar a unos cien mil salvadoreños más. No ofrecían otra respuesta que la de 1932, pero amplificada. Aunque no se alcanzó esa canridad, se estuvo cerca. En la actualidad, esas muertes son negadas o interpretadas como simples accidentes. Pedir responsabilidades está fuera de lugar, porque llevaría a exponer ante la sociedad la criminalidad del sistema. Mientras tanto, éste sigue operando a costa del bienestar de millones de salvadoreños, quienes se ven obligados a huir al extranjero o a resignarse a vivir para siempre en pobreza o incluso en miseria, tal como lo acaban de evidenciar los terremotos.

La ideología anticomunista proporcionó el pretexto. Comunistas eran los campesinos despojados de sus tierras que se alzaron para reclamar lo que consideraban propio desde tiempos inmemoriales; comunistas eran los que volvieron a reclamar tierras y justicia en la década de 1970, y quienes, ante la incapacidad del sistema para admitir reformas, se alzaron en armas; comunistas eran todos aquellos que, desde comienzos del siglo $\mathrm{XX}$, lucharon por introducir cambios en la estructura social y económica de El Salvador. El cambio social mismo ha sido y continúa siendo sinónimo de comunismo. La clase dominante salvadoreña se ha atrincherado en la ideología anticomunista para defenderse contra los cambios que la existencia de mayorías empobrecidas, los reformadores sociales, los profetas y las circunstancias históricas reclaman. Por eso, cuando los más audaces se deciden a trabajar para introducir algún cambio suelen hablar de transformación. La ideología anticomunista se volvió así un baluarte contra quienes pedían una economía más equitativa, un Estado democrático de derecho y un ordenamiento jurídico. El obstáculo más grande para la modernización de El Salvador se encuentra en esta clase temerosa de perder su poder y sus privilegios y renuente a verse sometida a la voluntad popular y a la ley.

Es así como para esta tradición de progreso y anticomunismo, los retos que enfrenta El Salvador después de los terremotos siguen siendo los mismos de antes. En Madrid, el gobierno se propuso hablar mucho de tecnología, modernización, bienestar y participación ciudadana e incluso de auditoría social, sin duda, para impresionar a los países donantes ahí convocados por el Banco Interamericano de Desarrollo; mientras que en El Salvador, voces diversas hacían llamados a la unidad para construir ese nuevo El Salvador de prosperidad y libertad - léase anticomunismo-, en el que el gobierno de ARENA todavía sigue creyendo. La cuestión es si vale la pena sumarse a este esfuerzo.

\section{Una unidad nacional cuestionable}

Es indiscutible que la superación de una destrucción tan devastadora como la ocasionada por los terremotos sólo es posible si existe un plan 
nacional alrededor del cual se pueda construir un consenso lo suficientemente amplio como para que en su ejecución participasen las fuerzas sociales más representativas y determinantes, incluyendo a los partidos políticos y a los gobiernos central y local. Esto por dos razones principales, porque la magnitud de la devastación es tal que pone fuera del alcance de cualquiera de estas fuerzas la resolución de los problemas que aquejan al millón y medio de salvadoreños damnificados y al país mismo como totalidad. En este sentido, El Salvador tiene camino recorrido en el trabajo de la Comisión Nacional de Desarrollo y su plan de nación. La otra razón es que la superación de la crisis exigirá sacrificios tales que sólo podrán ser soportados si se parte de un consenso. Los reducidos recursos financieros conseguidos en Madrid han hecho evidente que, tarde o temprano, El Salvador tendrá que recurrir a sus propios recursos para cubrir sus necesidades más urgentes. Esto significa un empleo más racional del gasto público y un incremento de la carga tributaria, que, por razones de equidad y solidaridad, debiera recaer en quienes más se han beneficiado de la política neoliberal de ARENA. Este reducido sector privilegiado riene ante sí la oportunidad para demostrar su nacionalismo, siendo solidario con aquellos otros compatriotas que más han sufrido no sólo por los terremotos, sino por más de un siglo de negación de oportunidades. Estos, por su lado, tendrán que predisponerse a colaborar de manera activa, no sólo en la construcción de sus viviendas, sino también en la organización de sus comunidades locales. Ias instituciones y organizaciones intermedias tienen un papel crucial en este esfuerzo, pero sin olvidar su carácter intermediario.

Dicho lo anterior, la siguiente cuestión a dilucidar es si la propuesta gubernamental puede ser asumida por las fuerzas sociales más representativas. La discusión tiene su importancia, porque todavía no existe claridad sobre el plan que el gobicrno adoptará. Si ha de haber consenso, se ha de conocer con anticipación en qué se está de acuerdo. Más aún, para que haya consenso, la propuesta, cualquicra que ésca sea, debe ser discutida por las partes que formarán parte de dicho acuerdo. El consenso no es algo dado, sino que se construye en la discusión. Sin embargo, la línea adoptada por el gobierno es otra. Reclama unidad alrededor de su propuesta, sin que se sepa a ciencia cierta en qué consiste ésta y, por supuesto, sin haberla discutido. En el contexto de la reunión de Madrid, el gobierno habló de dos propuestas: la de la Comisión Nacional de Desarrollo, la cual habría sido ajustada a las circunstancias creadas por los terremotos - Elementos para la reconstrucción y el desarrollo de El Salvador. Una contribución desde la sociedad civil_, y la suya propia, ya citada. Por un lado, afirmó que asumía la primera, pcro sin retirar esta última. Por lo tanto, lo más probable es que ésta sea la que prevalezca y la que también haya presentado ante el grupo consultivo. Es la más coherente con su manera de pensar. Aparte que el gobierno de Flores todavía no se ha apropiado formalmente del plan de la Comisión Nacional de Desarrollo. Hacerlo supondría abandonar algunas de las propuestas neoliberales más im- 
purrantes. lintonces, la cuestión se centra en si la propuesta gubernamental, ci los términos en los cuales ha sido planteada, puede ser asumida por una unidad amplia como la que se reclama - y se necesita.

Continuar con la misma política económica, tal como propone el gobierno, implica conservar una estructura que privilegia al 20 por ciento de la población donde se concentran el ingreso nacional y casi todas y las mejores oportunidades, al mismo tiempo que excluye a la mayoría, a la cual mantiene en la pobreza y en la pobreza extrema. La existencia de esta estructura de desigualdad e injusticia no puede ser puesta en duda después de los terremotos. Conservarla sería injustificable, al menos desde el lado de los excluidos. El propósito de construir con equidad y justicia desaparece cuando al mismo tiempo se propone mantener la política económica existente por considerarla indispensable. Esa política es la que ha generado no sólo una organización social injusta, sino también un modelo cuya lógica de producción y distribución se encuentra en entredicho. Los datos hablan por sí mismos. La producción es menor y bastante más cara $y$, por consiguiente, menos competitiva hoy que hace diez años. Si la equidad se mide utilizando los salarios reales, resulta que el índice de los salarios mínimos reales es casi el 25 por ciento inferior al de 1988, mientras que la concentración del ingreso es desproporcionadamente elevada y la estructura tributaria es, sin lugar a dudas, recesiva. Aun cuando se constatan avances en la reducción de la pobreza, en la calidad de la educación, en la disminución del analfabetismo y en el aumento de la esperanza de vida, más del $\mathbf{4 0}$ por ciento de los hogares, es decir, casi tres millones de salvadoreños, vivía en pobreza antes de los terremotos, y de esos tres millones, poco más de un millón lo hacía en extrema pobreza. Esto último significa vivir con un poco más de un dólar al día en la ciudad y con un poco más de medio dólar en el campo.

Este sector mayoritario es el que ha sido más golpeado por los terremotos. Es una mayoría que no tiene acceso a los bienes que necesita, lo cual, por otro lado, explica la insuficiencia de la demanda interna y el estancamiento del crecimiento económico. Más aún, avances como los señalados arriba son frenados de inmediato por un producto interno bruto que todavía se encuentra por debajo del alcanzado hace veintidós años. La tasa de crecimiento del año pasado es la segunda más baja desde 1992, el desempleo aumentó a lo largo del año 2000, así como también la tasa de inflación, pero los salarios mínimos reales disminuyeron, los déficit fiscal y comercial aumentaron, el ahorro corriente arrojó un saldo negativo por primera vez en varios años, los términos de intercambio se deterioraron, poniendo al descubierto la poca competitividad del país en el comercio internacional, la canasta básica fue encarecida al ser incluida en el impuesto al valor agregado y el subsidio a la electricidad fue suprimido. La clara tendencia a favorecer la desigualdad en la distribución del ingreso, la existencia de una legislación poco clara, y aun contradictoria, la inseguridad general y la ausencia del Estado en áreas vitales 
para regular sus actividades y promover la equidad y el desarrollo humano es aprovechado por la clase dominante para perpetuarse en el poder y el privilegio, mientras que el resto de la población, incluida cada vez más la clase media, se encuentra desprotegido ante las arbitrariedades de la burocracia estatal y de una estructura social centralizada y corrompida.

El documento de Madrid no desconoce esta realidad, pero la disimula al señalar algunos éxitos parciales conseguidos en el campo de la macroeconomía y del desarrollo social y al proyectar unos deseos contra los cuales no se puede argumentar. Los dos éxitos más notables en la macroeconomía son la estabilidad de los precios y del tipo de cambio, pero el documento pasa por alto las deficiencias del desempeño fiscal y del secror externo. Al señalar el aumento de la esperanza de vida y el control de ciertas enfermedades infantiles, silencia - no obstante encontrarse en la misma fuente- la desnutrición crónica de la población menor de edad, la vulnerabilidad de las madres y la persistencia del dengue hemorrágico. A la vinculación del país con el mundo se le atribuye un potencial de rransformación enorme, pero no se examina por qué esa vinculación sigue siento extremadamente débil. A finales del año pasado, el mismo presidente Flores reconoció que la economía salvadoreña adolecía de problemas estructurales graves. En ese entonces, defendió la cuestionada dolarización, argumentando que la economía se encontraba "entrampada". Paradójicamente, El Salvador recibe la mejor calificación de riesgo de la región centroamericana y la máxima en cuanto a libertad económica en el subcontinente latinoamericano - otro de los logros subrayados por el documento de Madrid-, pero entre los países centroamericanos, ocupa el penúltimo lugar, en crecimiento económico.

El propósito de construir con equidad y justicia desaparece cuando al mismo tiempo se propone mantener la política económica existente por considerarla indispensable.

Del disimulo ance los países industrializados convocados en Madrid se pasa a la falta de claridad cuando se llega a las prioridades gubernamentales. No existe relación articulada entre los criterios y las llamadas "áreas del plan de recuperación" —una larga lista de necesidades, agrupadas por temas. $\mathrm{Ni}$ siquiera en las prioridades hay claridad. En realidad, no se establecen prioridades $y$, por consiguiente, aparecen en el mismo nivel prioridades excluyentes. Simultáneamente, se propone "resolver las necesidades inmediatas de la población" y "la reactivación de la agricultura... bajo un enfoque de comperitividad y sostenibilidad". Casi de forma inmediata, el gobierno destinó el equivalente al 25 por ciento del presupuesto nacional para reactivar la producción de café, la cual no es, de ninguna manera, una de "las necesidades inmediatas de la población”. Esta decisión no puede justificarse alegando la 
creación de empleo, porque no lo crea en la cantidad que asegura y porque cuando los precios internacionales son altos y la producción es elevada, los salarios pagados nunca han llegado a cubrir la canasta básica, aparte de que es un empleo estacional, ni la conservación del bosque que da sombra a los cafetales, porque aquél no sólo puede conservarse, sino que además debiera expandirse, sin necesidad de mantener éstos. Al privilegiar esta actividad, el gobierno deja fuera a los otros sectores agrícolas, quizás más vulnerables $y$, ciertamente, más urgidos de programas especiales de reactivación. El gobierno no sólo contradice una de las tesis fundamentales del neoliberalismo, aquella que prohíbe intervenir en el mercado, sino que, además, actúa en contra de su fallo que, en teoría, es inapelable. De acuerdo al mercado, la producción cafetalera no es rentable, ni sostenible, ni competitiva. Por lo tanto, desde esa lógica, no se justifica continuar estimulando su producción; aunque sí desde la ideología del progreso anticomunista, que nació en el seno de la elite cafetalera y cuyos miembros más poderosos en la actualidad constituyen un núcleo de poder dentro del partido de gobierno.

Es muy difícil, si no imposible, construir una unidad nacional cuando el gobierno que invita a participar se inclina por conservar una política económica cuyo fracaso, en términos de desarrollo humano sostenible, es evidente, y por privilegiar a una reducida clase social que, de por sí, ya es bastante rica, privilegiada y poderosa.

En los llamados "lineamientos estratégicos" rampoco se encuentra un hilo conductor. Aunque están presentes y su existencia es la que lleva al gobierno a formular tales lineamientos, los damnificados y los pobres no constituyen el centro, sino que el centro lo ocupa la reactivación de la economía. Aquéllos entran de modo indirecto, como beneficiarios del empleo creado por esta última. En el mismo nivel estratégico se encuentran "la descentralización económica y política" y "la ejecución de grandes proyectos regionales", la "infraestructura para la conectividad" y "la desconcentración de las zonas urbanas y la integración regional", implicando tal vez que no pueden haber proyectos regionales sin descentralización y que se desearía enviar al exceso de población urbana a buscar empleo en la región. En la participación, el gobierno incluye a los partidos políticos, las municipalidades, los intelectuales, los expertos, los empresarios y las organizaciones no gubernamentales, pero deja fuera a la gente - en la mejor hipótesis, presupone que ésta está incluida de alguna manera en las organizaciones no gubernamentales. La generación de empleo y la formación del recurso humano —o como ya es moda, el capital humano- se pretende orientar a "disminuir vulnerabilidades e insertar al país en la economía mundial", pero no para promover la realización de las 
personas en cuanto seres humanos. Sigue, pues, predominando una visión mercantilista del empleo y de la persona.

Debe existir, entonces, una razón poderosa para, ante estos resultados y ante estas limitaciones, empeñarse en mantener "las condiciones que han permirido... gozar de estabilidad económica en los últimos años", que, por lo tanto, "deben mantenerse" por ser "indispensables para obtener recursos externos, para propiciar el desarrollo del país y para garantizar mayor bienestar a la población". La única razón admisible sería "convertir la tragedia en oportunidad" para estimular la economía, a través de la gran empresa privada. Lamentablemente, en esto, el gobierno salvadoreño no está sólo, porque algunos de los países industrializados que acudieron a Madrid fueron con la idea de orientar la cooperación a las inversiones y al comercio. Esto significa abandonar la idea original que los reunió por primera vez, en Estocolmo, hace algunos años. En ese entonces, la idea era promover un desarrollo humano sostenible en la región centroamericana; ahora, con el pretexto de que tales compromisos ya fueron superados, han decidido modificar el enfoque de su participación, destinándolo a la construcción de infracstructura nucva o dañada, en lugar de dirigirlo hacia la transformación de la sociedad. De esta manera, se pierde una oportunidad para desarrollar un programa multilateral contra la vulnerabilidad natural y social del istmo centroamericano.

En el caso de El Salvador, la estrategia del gobierno de ARENA consiste en destinar la mayor parte del financiamiento que pueda conseguir a raíz de los terremotos - el cual, de hecho, está resultando ser mucho menos de lo esperado-, no para favorecer en directo a los damnificados y a los pobres, sino para intentar "desentrampar" la economía, que sus propias políticas han

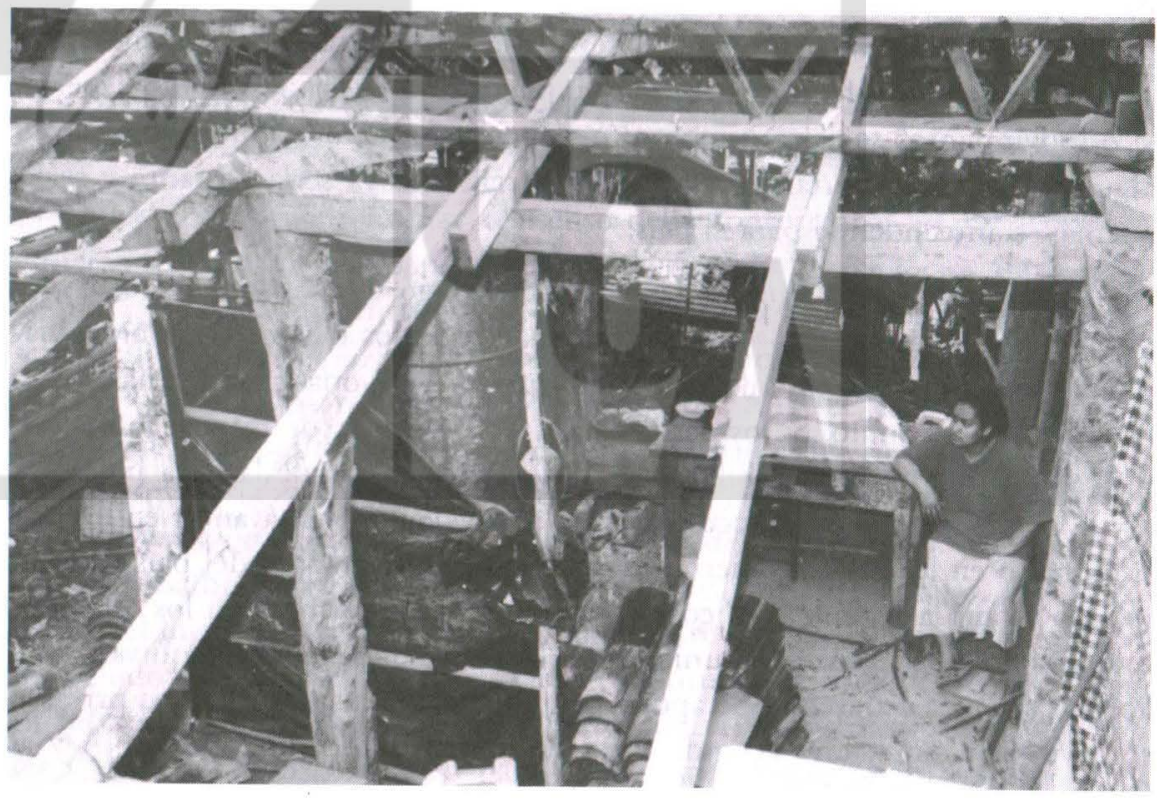


estancado. La idea, al parecer, es que este financiamiento sustituya a la inversión extranjera, que tampoco ha llegado a El Salvador, a pesar de sus buenas calificaciones de riesgo y libertad económica. La prioridad, por consiguiente, no la constituyen los damnificados, ni los pobres, sino la gran empresa privada. De esta manera, el gobierno de ARENA estaría desempeñando el papel que se ha asignado a sí mismo: facilitar a la gran empresa privada sus negocios, renunciando al mismo tiempo a intervenir en la actividad económica.

Es muy difícil, si no imposible, construir una unidad nacional cuando el gobierno que invita a participar se inclina por conservar una política económica cuyo fracaso, en términos de desarrollo humano sostenible, es evidente, y por privilegiar a una reducida clase social que, de por sí, ya es bastante rica, privilegiada y poderosa. De este proyecto sólo podrán participar el gobierno de ARENA, su promotor; los grandes empresarios, nacionales y extranjeros, sus ejecutores y beneficiarios directos, y aquellos intelectuales y tecnócratas que intentan justificarlos en vano con sus falacias y sofismas.

\section{El desafío de la unidad nacional}

No obstante la unidad es posible, si se llegan a encontrar puntos de convergencia, a través de un proceso de diálogo y concertación, sin duda, complicado, por el número y el carácter de la representatividad de las fuerzas sociales que debieran tomar parte en él, e incluso polémico, por la multiplicidad de visiones e intereses y las diferencias, aparentemente insalvables, entre algunas de ellas; pero, a la larga, este proceso es insoslayable, si se está interesado en buscax la viabilidad de El Salvador e incluso de la región centroamericana. Tal vez hablar de unidad sea demasiado ambicioso en estos momentos, dada la extrema polarización social y económica desde la que se parte, pero sí pueden construirse consensos graduales y cada vez más inclusivos que, sin negar las diferencias existentes, puedan facilitar a las diversas fuerzas y, o movimientos sociales comenzar a trabajar con dedicación hasta alcanzar algunos puntos importantes de convergencia. Esto ya sería bastante y sería, además, transcendental para el país.

Habría que volver, pues, a la mesa de diálogo - así como se hizo para poner fin a la guerra civil- para concertar acuerdos básicos que hagan viable la transición posterior a los terremotos para las mayorías salvadoreñas y para el pais en su conjunto. Si los participantes se comportan de manera razonable, tienen un mínimo de sensibilidad social y cierto sentido de la ética política y social, a medida que este proceso avance, se puede también avanzar en unidad nacional o en lo que el gobierno prefiere llamar integración del país consigo mismo y con la región. Una cosa es evidente, en la forma y en los términos que el gobierno plantea la unidad en la actualidad, lo cual equivaldría a aceptar su línea estratégica de apoyo incondicional a la gran empresa privada, su invitación no tendrá acogida fuera de los círculos afines a ARENA y al 
gran capital. Tampoco la tendrá si sigue manipulando como hasta ahora para ocultar sus verdaderas intenciones. En Madrid, el gobierno salvadoreño hizo un planteamiento bastante diferente al que la Comisión Nacional de Desarrollo presentó en San Salvador con el propósito de ganarse a la opinión pública. Mal hace la Comisión Nacional de Desarrollo en prestarse a estos juegos gubernamentales, pues corre el peligro de perder el apoyo social acumulado al convertirse en mero instrumento de los planes gubernamentales.

Un proceso de concertación semejante habría que impulsar para conseguir que la integración regional avanzase de forma más decidida y expedita. Algunos de los proyectos presentados en Madrid, en particular el plan mexicano Puebla-Panamá, recogen intereses regionales importantes, los cuales pueden servir como punto de partida. La realización de estos proyectos depende de que cada uno de los participantes renuncie a una parte de su soberanía y a su visión tradicional de la sociedad y del país mismo para conformar una realidad mayor, con mayor potencial para el desarrollo humano sostenible, con una soberanía realmente superior $y$, por ende, con mayor fuerza para negociar con los otros bloques de países que conforman la realidad del mundo actual. En este sentido, el plan mexicano Puebla-Panamá ofrece una plataforma novedosa que no debiera ser desaprovechada por los países del istmo, pero que, de asumirla, supondría cambios sustanciales en la mentalidad y las políticas nacionales. Pero nada de esto será posible sin un consenso mínimo de los respectivos gobiernos, empresarios y fuerzas sociales.

La unidad será nacional cuando coloque en el centro de sus preocupaciones y tareas a esas mayorías.

En este sentido, el discurso nacionalista de la elite política y económica es contradictorio, porque, en el fondo, defiende intereses opuestos a los de esas mayorías.

En el caso salvadoreño, ese consenso debe conformarse no alrededor del esfuerzo gubernamental para continuar facilitando los negocios de la gran empresa privada, sino en torno al esfuerzo por cerrar la enorme brecha que separa al 20 por ciento de la población que percibe dieciséis veces menos ingreso que el 20 por ciento que más percibe. Aunque esta alternativa no excluye al gran capital, cl cambio de perspectiva es determinante al decidir las políticas y establecer las metas, porque subordina sus ganancias a los intereses de la mayoría de la población y, en definitiva, del bien común. De hecho, el cierre de esa brecha se encuentra entre las metas gubernamentales, pero al no ocupar el lugar que debicra - cs una más entre otras-, su cumplimiento es muy dudoso. Si el cierre de esta brecha constituye no un reto, sino el reto de El Salvador, debiera determinar, en consecuencia, las políticas más importantes y debiera ser el parámetro para evaluar sus resultados. El desafío de El 
Salvador lo siguen constituyendo sus mayorías, cuyo número ha crecido en la última década, así como han aumentado su empobrecimiento y sus posibilidades reales para salvar el abismo que las separa de una vida humana y digna. Es cierto que este reto también es reconocido por el gobierno, pero aquí se está proponiendo algo radicalmente diferente.

Aparentemente, la propuesta gubernamental la conforman retos diversos y desordenados, sin ningún orden de prioridades; pero al analizar con detenimiento su planteamiento, la opción gubernamental es clara. El gobierno de ARENA privilegia la reactivación de la economía salvadoreña, favoreciendo a la gran empresa privada, nacional y extranjera, y subordinando los otros retos a esta opción. En cambio, aquí se propone colocar en el centro del proceso a las mayorías salvadoreñas empobrecidas y damnificadas, porque ellas, por sólo el peso de su número, constituyen el problema de El Salvador que, en cuanto tal, es además un problema ético. En este sentido, es necesario ir mucho más allá de lo que el gobierno propone, porque tiene mucho más de codicia que de responsabilidad con el bien común y, en cuanto tal, sólo traerá más desigualdad y pobreza. Optar por este planteamiento es optar por la injusticia. La reactivación de la economía y los demás retos, por lo tanto, deben colocarse al servicio de la solución de este problema principal. Sólo así la integración o la reconciliación de la sociedad y del país adquiere contenido real. En la medida en que se pueda avanzar en esta dirección, se irá construyendo una unidad real, al ir haciendo posible la unión de lo que está separado por una brecha económica y social, y en la medida en que esa unidad sea más universal, en cuanto comprenda cada vez a más grupos y sectores sociales, podrá decirse que esa unidad adquiere carácter nacional. Este proceso de construcción de unidad nacional dejará como resultado una realidad social nueva, en la cual sus integrantes también deberán experimentar transformaciones importantes. Desde este proceso de construcción de una nueva realidad social, integrada por hombres y mujeres nuevas, el paso a la integración regional y a la inserción en el mundo será más seguro y beneficioso para la sociedad en su conjunto.

No obstante, este proceso presenta dificultades a las cuales hay que saber prestar atención para evitar que el proceso no se estanque o se desvíe. La primera de estas dificultades se deriva de una doble prioridad imposible de sostener a mediano plazo: la reactivación de la economía y las mayorías pobres y damnificadas. Aunque estas prioridades no son excluyentes, la primera debiera estar subordinada a la segunda y proporcionar la dirección del proceso. Mientras se mantenga que lo más importante es reactivar la economía, favoreciendo para ello al gran capital, otorgándole nuevos privilegios, de antemano se puede adelantar que la unidad será imposible. Es más, desde una perspectiva ética no se puede apoyar un proyecto que expresamente mantenga la brecha que divide a la sociedad salvadoreña en la actualidad. 


\section{La posición de El Salvador y de Centroamérica en el mundo actual exige nuevas ideas sobre la nación \\ y la nacionalidad, y un nuevo credo del cual desaparezca el anticomunismo y el progreso sea comprendido de una manera más objetiva y real [...] Una de esas ideas nuevas que, además, es crucial para el desarrollo humano, es la participación ciudadana.}

La unidad será nacional cuando coloque en el centro de sus preocupaciones y tareas a esas mayorías. En este sentido, el discurso nacionalista de la elite política y económica es contradictorio, porque, en el fondo, defiende intereses opuestos a los de esas mayorías. Es el viejo mecanismo de la antigua elite cafetalera, que convirtió sus intereses particulares en nacionales. Mientras estas elites no se comprometan a trabajar para superar el desafio que plantean las mayorías salvadoreñas, su nacionalismo no es más que una ideología que oculta sus verdaderos intereses y les permite controlar el país de manera parrimonial. Mientras no haya cambios radicales, el desarrollo humano de El Salvador avanzará penosa y lentamente, y su integración en la región y en el mundo no será fácil. En este sentido, el plan de nación, que cuenta con un consenso importante, podría ser asumido por estas elites como punto de partida para llegar a un compromiso formal con lo que ahí se propone para impulsar un desarrollo humano mínimo. Aunque el compromiso es de todos, es más de aquellos que más se han beneficiado de los recursos salvadoreños, de los más favorecidos por la política gubernamental de la última década y, en consecuencia, de quienes han podido acumular más riqueza. En vez de ello, sin embargo, la clase dominante busca la forma de trasladar esta responsabilidad a otros. Primero lo intentó con las naciones industrializadas, pero éstas, aparte del egoísmo natural del que absolutiza la riqueza y la comodidad, le reclamaron su poco esfuerzo, reflejado en la baja carga fiscal salvadoreña; este fracaso la ha llevado a colocar grandes expectativas en los emigrantes, quienes además de mantener a flote la economía nacional en la década pasada, ahora también cargarán con el financiamiento de buena parte de la reconstrucción y, finalmente, la diferencia será cubierta con impuestos regresivos.

Si las clases dominantes llegaran a comprometerse con el bienestar de las mayorías salvadoreñas y con el bien común del país, esto no será suficiente para enfrentar con éxito el desafío planteado, porque aquéllas no controlan los factores externos, que determinan el comportamiento del mercado mundial. La caída sostenida de los precios del café o la subida sostenida del precio de los hidrocarburos o las oscilaciones de las tasas de interés de los mercados financieros o la apertura o el cierre de los mercados internacionales a la producción salvadoreña son determinados por los intereses del gran 
capital transnacional y no por las conveniencias del desarrollo humano de los salvadoreños o de los centroamericanos. En su discurso ante la Asamblea General de Naciones Unidad del año pasado, el presidente Flores reclamó, aunque sin elaborar demasiado, el derecho a vender, es decir, el derecho a disponer de mercados donde colocar la producción nacional. En otras palabras, el derecho a que el mercado sea realmente libre. En la práctica, el mercado no es tan libre como lo proclama la retórica de los países industrializados, los bancos multilaterales y los creyentes del neoliberalismo, puesto que aquéllos levantan barreras y otorgan subsidios, según sus conveniencias particulares, entorpeciendo la competencia. Si algo han puesto en claro los terremotos en El Salvador y el huracán Mitch en Honduras y Nicaragua es que a los países más industrializados y ricos —el G-7- no les preocupa en lo más mínimo si los países centroamericanos se integran en los círculos de la riqueza mundial o permanecen al margen. El destino de Centroamérica no les quita el sueño - a no ser que ponga en peligro sus planes. Por lo tanto, de la simple apertura al mundo no se puede esperar una respuesta automática a las necesidades económicas de países como El Salvador, sino que habrá que luchar por ella en los espacios internacionales. Si la batalla la dan no países aislados, sino bloques regionales -en realidad, es una lucha de bloques - la cuestión ya no es la nación, ni la nacionalidad, sino la región, la interdependencia, la co-responsabilidad, la solidaridad, etc. La posición de El Salvador y de Centroamérica en el mundo actual exige nuevas ideas sobre la nación y la nacionalidad, y un nuevo credo del cual desaparezca el anticomunismo y el progreso sea comprendido de una manera más objetiva y real. Por consiguiente, nadie, exceptuando a El Salvador y al resto de los países centroamericanos, se ocupará del desarrollo humano sostenible.

Una de esas ideas nuevas que, además, es crucial para el desarrollo humano, es la participación ciudadana. Sin embargo, el concepto requiere de precisión rigurosa, porque se usa con demasiada discrecionalidad, implicando realidades no sólo divergentes, sino incluso contradictorias. El gobierno salvadoreño, sumándose a la corriente universal, no sólo habla mucho de la participación ciudadana, de promoverla, de tomarla en cuenta, etc., sino que se considera, de manera abusiva, uno de sus representantes privilegiados. Según su concepción, el papel de la participación ciudadana consiste en desarrollar los proyectos locales y nacionales, sobre todo en las áreas de salud y educación, con lo cual la gente y sus organizaciones quedan fuera y aunque promete el establecimiento de una auditoría social, la experiencia demuestra que ni ésta ni la formal de la Corte de Cuentas son bien vistas. Esta concepción coincide con la de los bancos mulrilaterales, que sólo consideran la participación de la llamada sociedad civil en el desarrollo de proyectos, porque baja sus costos y garantiza mejor su ejecución, pero no como medios para promover los intereses comunes. Es más, habría áreas reservadas, en las cuales su participación no sólo no es bien vista, sino que está expresamente descartada, 
aun cuando la afectan de forma directa e inmediata. De esta concepción se deriva una segunda reducción del concepto de la participación ciudadana: de una forma arbitraria se tiende a identificar a las organizaciones no gubernamentales con la sociedad civil, cuando no se las considera como sus represenrantes legírimas. Esro no siempre es así. Existen no pocas organizaciones no gubernamentales que representan intereses y ejecutan proyectos sin considerar a la población beneficiada o afectada. Para que haya unidad la participación ciudadana debe tender a ser directa y a influir en todas las decisiones importantes de la vida social, pero al mismo tiempo debe tener voz propia y contar con espacios e instrumentos para promover sus incereses.

Crear espacios de participación ciudadana, prestar atención a sus reclamos y demandas y promover su fortalecimiento implica cambiar bastantes prácticas de la política consuetudinaria salvadoreña y, con toda probabilidad, también reformas en el orden legal vigente. No se puede seguir creyendo que la vinculación con el mundo tendrá éxito conservando intacto lo interno y, o creer que desde esa vinculación se podrán producir los cambios que El Salvador está reclamando. La integración de El Salvador en el mundo va mucho más allá de la actividad comercial, que es donde se centran en la actualidad tanto el gobierno como el gran capital. El éxito es más probable si se lleva a cabo desde un proceso de transformaciones internas. Es, por lo tanto, un sin sentido pretender continuar como antes de los terremotos.

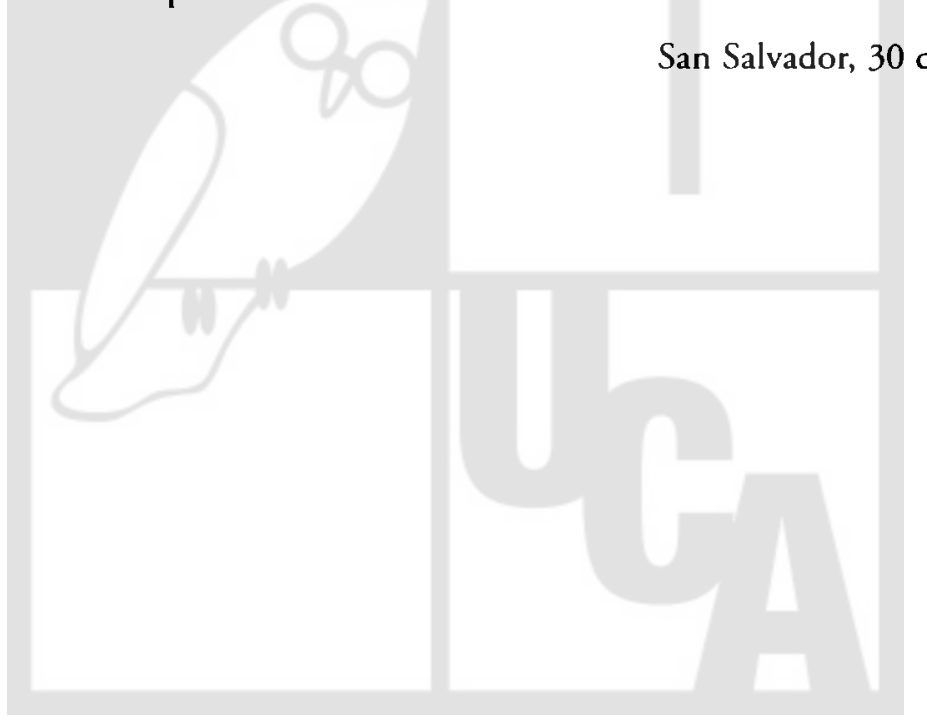

